\title{
The Effect of Social Justice Advocacy and Ethical Sensitivity on the Social Entrepreneurial Intention of High School Students
}

\author{
Joseph $\mathrm{Kim}^{1}$ \& Byeonghwa Park ${ }^{2}$ \\ 1 Livingston High School, Livingston, USA \\ 2 School of Management and Marketing, College of Business and Public Management, Kean University, USA \\ Correspondence: Dr. Byeonghwa Park, School of Management and Marketing, College of Business and Public \\ Management, Kean University, Union New Jersey 07038, USA. E-mail: bypark@kean.edu
}

Received: August 19, 2019

doi:10.5539/ijbm.v14n11p18

\author{
Accepted: September 20, 2019 \\ Online Published: October 9, 2019 \\ URL: https://doi.org/10.5539/ijbm.v14n11p18
}

\begin{abstract}
The objective of this study was to assess the effect of ethical sensitivity and social justice advocacy on social entrepreneurial intention, and also, examined the impact of empathic concern and perspective taking on social justice advocacy and ethical sensitivity respectively. Another objective is to assess these relationships using the high school student population. This study collected the data from 201 high school students in the east coast area in the U.S. The students were randomly selected and invited to the survey. Path analysis was used to test the suggested hypotheses. The results indicated that high school students with a high level of social justice advocacy and ethical sensitivity showed stronger social entrepreneurial intention. Also, empathic concern was significantly related to social justice advocacy, while perspective taking was associated considerably with ethical sensitivity. Our study finds that ethical sensitivity and social justice advocacy will foster SE intention among high school students. Unlike adult groups, high schools students are under development of their ethical system and the value and attitude toward social issues. Education or training can play a critical role in high school students' ethical system or attitudes toward social justice. There should be more emphasis on ethics and social justice in the curriculum of high schools.
\end{abstract}

Keywords: Social Entrepreneurial Intention, Social Justice Advocacy, Ethical Sensitivity, High School Students

\section{Introduction}

Countries suffer from various types of social issues regardless of their state of economic development. Underdeveloped nations have trouble with issues of poverty, education, health, and war while developed nations are struggling with social issues such as income inequality, homelessness, domestic abuse, and discrimination. This commonality exemplifies the failure of the public and private sector. Resultantly, disappointed people have turned to social entrepreneurship with the hope that this new form of entity can help alleviate social problems with innovative ideas. Social entrepreneurship refers to the activity of solving social problems in innovative ways by applying entrepreneurial skills. For decades, people have witnessed many successful cases of social entrepreneurship such as Gramin Bank, Kaboom, and Tom's Shoes. Correspondingly, social entrepreneurship has gained widespread attention from researchers and practitioners.

Additionally, with the rising influence of media and SNS, teenagers have expressed a significantly vested interest for social issues. Beyond merely expressing concern over these issues, they have taken decisive action to solve these problems. For example, in the wake of the Parkland school shooting, high school students initiated the "\#NeverAgain" movement to advocate for reduced gun violence. High school students are also provided more opportunities to learn how to initiate change as social entrepreneurship camps and programs are created.

However, although social entrepreneurship has gained popularity among teenagers, there have been few studies on social entrepreneurship for high school students. The current study aims to explore the antecedents of SE intentions of high school students.

Social entrepreneurship intention refers to the intent to pursue a social mission by starting a business or launching a social venture (Bacq \& Alt, 2018). It can be described as a person's intention to launch a social enterprise to advance social change through innovation (Prieto et al., 2012). SE intention is a good predictor of actual social entrepreneurship. SE intentions are a subject of growing interest in the entrepreneurship literature (Linan \& 
Fayolle, 2015). There has been plentiful research on the antecedents of SE intention including prior experience with social organization (Hockerts, 2015), social worth (Bacq \& Alt, 2018), education and social capital (Ernst, 2012), gender and personality (Nga \& Shamuganathan, 2010), proactive personality and hope (Prieto, 2011), emotional intelligence and creativity (Tiwari et al., 2017), and social innovation orientation and social vision (Cavazos-Arroyo et al., 2017).

This study considers social justice advocacy and ethical sensitivity as antecedents of SE intentions. Ethical sensitivity refers to the ability to recognize that a decision making situation has ethical content and the ascription of importance to the ethical issues composing that content (Sparks \& Hunt, 1998). Social justice advocacy refers to the attitude where an individual seeks to ensure that opportunities and resources are distributed fairly so that every person has the same right to assess resources regardless of gender, race, age, disability, religion, and education (Fouad et al., 2006). In the consideration of the nature of social justice advocacy and ethical sensitivity, it is highly likely that they are associated with SE intentions. However, these two variables were rarely studied as an antecedent of SE intentions.

This study contributes to the existing literature on social entrepreneurship by filling the gaps: First, this study examined the influence of ethical sensitivity and social justice advocacy on SE intention. Second, this study expanded the scope of social entrepreneurship research to the high school population, which is not the traditional target population.

The research questions of the current study are as followed:

How do Ethical Sensitivity and Social Justice Advocacy influence SE intention?

How will Empathic Concern influence Social Justice Advocacy?

How will Perspective Taking influence Ethical Sensitivity?

In the following section, the paper will discuss the development of the hypotheses, research methodology, findings, and conclusions.

\section{Literature Review}

\subsection{SE intention}

Social entrepreneurship intention refers to the intent to pursue a social mission by starting a business or launching a social venture (Bacq \& Alt, 2018). It can be described as a person's intention to launch a social enterprise to advance social change through innovation (Prieto et al., 2012). SE intention is a good predictor of actual social entrepreneurship and it is a subject of growing interest in entrepreneurship literature (Linaan \& Fayolle, 2015).

According to the Planned Behavior Theory (PBT), intentions are assumed to capture the motivational factors that influence behaviors; they are indications of how hard people are willing to try. People with stronger intention are willing to apply more effort, which in turn results in higher performance (Ajzen, 1991). In the PBT, the first determinant is the person's attitude, which is conceptualized as a positive or negative evaluation of performing of the behavior of interest (Jimmieson, Peach, \& White, 2008). The second determinant of intentions is subjective norm, which reflects perceived social pressure to perform or not perform the behavior (Jimmieson et al., 2008). The third determinant of intentions is perceived behavioral control. The perceived behavior control has been argued to indirectly affect behavior via intentions and/or have a direct effect on behavior (Ajzen, 1991; Ajzen \& Madden, 1986).

Although the PBT was originally developed in the area of psychology, the standard model of PBT can be adapted and changed to the specific domain of the study accordingly (Krueger et al., 2000). Mair and Noboa (2006) advanced the literature on the SE intentions based on the traditional model of the PBT. They discussed four proxy factors for the determinants of SE intentions: empathy, moral judgment, self-efficacy and perceived presence of social support, which correspond to each dimension of the PBT. In their model, moral judgement corresponded to subjective norm in the PBT while empathy was equated to attitude toward behavior in the PBT. For perceived behavior control in the PBT, self-efficacy was credited for internal behavior control while presence of social support was considered a proxy for external behavior control.

After Mair and Noboa's model (2006), plentiful studies explored various antecedents of SE intentions: prior experience with social organization (Hockerts, 2015), social worth (Bacq \& Alt, 2018), education and social capital (Ernst, 2012), gender and personality (Nga \& Shamuganathan, 2010), proactive personality and hope (Prieto, 2011), emotional intelligence and creativity (Tiwari et al., 2017), social innovation orientation and social vision (Cavazos-Arroyo et al., 2017). 


\subsection{Ethical Sensitivity}

Ethical sensitivity is defined as the ability to recognize that a decision making situation has ethical content and the ascription of importance to the ethical issues composing that content (Sparks and Hunt, 1998). According to Blum (1991), one of the most important moral differences between people is between those who fail to see and those succeed in seeing various moral features of situations confronting people. Ethical sensitivity consists of two aspects: personal ethical sensitivity and interpersonal ethical sensitivity. Personal ethical sensitivity reflects "a person's willingness to be in harmony with one's convictions, principles and moral values in one's choice while interpersonal ethical sensitivity reflects the external aspects of ethical sensitivity: utilitarian and behavioral motivations which are visible to others (Toti \& Moulins, 2017).

Ethical sensitivity is a prominent antecedent of ethical behavior. An individual with higher ethical sensitivity is likely to show concern over social problems and engage in more prosocial behavior to help people in need. Also, the operation of social entrepreneurship requires higher ethical standards compared with regular entrepreneurships. For example, the process to produce products and services should minimize waste or the emission of greenhouse gases and the enterprise should offer good compensation to the employees so that they are not exploited by the organization. An individual with low ethical sensitivity is less likely to develop the intention to establish social entrepreneurship because of its higher ethical standards in running the business.

Based on the discussion above, the study proposes the following hypothesis:

Hypothesis 1: High level of Ethical Sensitivity will have a positive association with SE intention.

\subsection{Social Justice Advocacy}

There are multiple definitions for social justice. Definitions differ in terms of the level of analysis or the emphasis on the outcome or process. Individual justice proposes that all individuals should have access to equal rights while distributive justice emphasizes that opportunities, resources, and power ought to be equitably distributed among individuals. A communitarian model of justice targets the decision-making process of how resources are distributed as key to social justice (Fietzeer \& Ponterotto, 2015). However, most definitions state that social justice necessarily seeks to change the status of marginalized groups within a society due to different identity statutes including, but not limited to, race, ethnicity, gender, sexual orientation, religion, age, disability, and socioeconomic status (Constantine et al., 2007; Fouad et al., 2006).

Social justice advocacy focuses on helping to ensure that opportunities and resources are distributed fairly to ensure equity when resources are distributed unequally and unfairly. This includes actively working to change social institutions, political and economic systems, and governmental structures that perpetuate unfair practices, structures and policies in terms of accessibility, resource distribution, and human rights (Fouad et al., 2006). The developmental model of social justice advocacy has been proposed wherein an individual (1) has contact with the reality of oppression and conflict, (2) develops an increased awareness of social injustice (3) formulates a sense of efficacy to bring about change, (4) develops a deeper understanding of the sociopolitical context of social issues, and (5) engages in advocacy to bring about change (Moeschberger et al., 2006).

The main goal of social entrepreneurship is to reduce any form of social injustice such as poverty, discrimination, education barriers, etc. Individuals who show a high level of social justice advocacy is more likely to engage in various activities to fix social problems, showing high level of SE intention.

Based on the discussion above, the study suggests the following hypothesis:

Hypothesis 2: High level of Social Justice Advocacy will have a positive association with SE intention.

\subsection{Empathic Concern and Social Justice Advocacy}

Empathy is defined as moral emotion (Moll et al., 2008), but is often regarded as a capacity to feel specific moral emotions (Haidt, 2003). Many empirical studies have shown that empathy fosters prosocial behavior while decreasing aggression and antisocial behavior (Batson 2010; Eisenberg, 2000; Tangney et al., 2007). Empathy consists of multiple dimensions: 1) perspective taking, 2) empathic concern, 3) fantasy, and 4) personal distress.

Empathic concern, which refers to the capacity to feel compassion and concern for others, is one of the dimensions of empathy. Empathy-altruism hypothesizes (Batson, 2010) that empathic concern promotes a genuine altruistic motivation: a motivational state with the ultimate goal of increasing the welfare of other people. Thus, EC facilitates behavior which is directed to help a person in need. There are plentiful studies to show that empathic concern is the strongest predictor of altruism (FeldmanHall et al., 2015; Lim \& DeSteno, 2016; Weng et al., 2015). Further, other studies have demonstrated that empathic concern is associated with the extent to which individuals are willing to sacrifice their own resources to help people in need (Edele et al., 2013). 
Thus, people with a high level of empathic concern will show sympathy to people who suffer from social problems and are more likely to engage in the activities to solve the social problems.

Based on the discussion developed in this section, the study developed the following hypothesis:

Hypothesis 3: High level of Empathic Concern will have a positive association with Social Justice Advocacy.

\subsection{Perspective Taking and Ethical Sensitivity}

Perspective taking refers to the ability of a person to imagine how situations look from the viewpoint of others and what interests, needs, and concerns that other people many have (Piaget, 1932). Perspective taking fosters moral cognition and moral conation process; adopting a another person's point of view helps to understand the consequences that actions can bring to that person, resulting in higher ethical sensitivity and awareness (Pohling et al., 2016). In the empirical study, employees with high levels of perspective taking showed more ethical decision making, reducing the acceptability of lying to protect the company (Cojuharenco \& Sguera, 2015). Cingel and Krcmar (2017) found that children's morality can be positively influenced by prosocial television exposure via promoting perspective taking. Hess et al. (2017) argued that to imagine and comprehend another's world view at some level of accuracy is the ground of ethical reasoning which works in conjunction with ethical sensitivity.

Thus, an individual who can understand another person's perspective is more likely to develop ethical sensitivity.

Based on the discussion above, the study proposes the following hypothesis:

Hypothesis 4: High level of Perspective Taking is positively associated with a high level of Ethical Sensitivity.

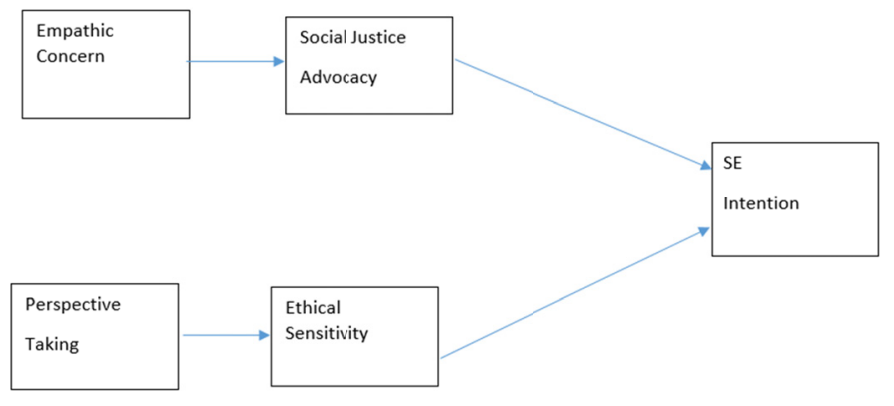

Figure 1. Research model

\section{Methodology}

\subsection{Participants}

We surveyed 210 high school students in the east coast area of the U.S. Nine responses were not completed so we dropped these incomplete responses. In total, we had 201 responses. Among the participants, freshman, sophomore, junior, and senior accounted for $14 \%, 24 \%, 24 \%$, and $34 \%$ of the data respectively. $47 \%$ percent of participants were female and 53\% were male. White, Black, Asian, and Hispanic accounted for $43 \%, 12 \%, 23 \%$, and $21 \%$ respectively.

\subsection{Measures}

Empathic Concern. We assessed the participants' empathic concern using the scale developed by Davis (1980). The scale has four items and the reliability of the scale is $\alpha=.81$. The example items include, "When I see someone being taken advantage of, I feel kind of protective towards them," "I often have tender, concerned feelings for people less fortunate than me," and "I would describe myself as a pretty soft-hearted person." The items were assessed on a five-point Likert scale, with " 1 " representing "strongly disagree" and " 5 " representing "strongly agree."

Perspective Taking. We assessed the participants' perspective taking, using the scale which is developed by Davis (1980). The scale has five items and the reliability of the scale is $\alpha=.68$, which is an acceptable level. The example items include, "Before criticizing somebody, I try to imagine how I would feel if I were in their place," "I sometimes try to understand my friends better by imagining how things look from their perspective," and "I try to look at everybody's side of a disagreement before I make a decision." These items were assessed on a five-point Likert scale, with " 1 " representing "strongly disagree" and " 5 " representing "strongly agree."

Social Justice Advocacy. We measured social justice advocacy using the scale developed by Miller et al. (2009). 
The scale has seven items and measures the degree to which the participant is concerned over social issues and tries to engage in the activities. The sample questions include, "reading about social issues," "volunteering your time at a community agency," and "donating money to an organization committed to social issues." The participants responded to the questions based on a seven-point Likert scale, with " 1 " representing "strongly disagree" and "7" representing "strongly agree". The reliability of the current study is $\alpha=.86$.

Ethical Sensitivity. We assessed participants' ethical sensitivity using the scale developed by Toti and Moulins (2017). The scale has seven items and the reliability of the scale is $\alpha=.81$. The example items include, "It is important for me not to harm others," "I consider the interests of others in my decision making," and "I have respect for others' culture, privacy, and personality, etc.” The items were assessed on a seven-point Likert scale, with " 1 " representing "strongly disagree" and "7" representing "strongly agree."

SE intentions. We assessed the participants' SE intentions using the scale developed by Linan and Chen (2009). The scale has six items and the reliability of the scale is $\alpha=.87$, showing high reliability. The example items include, "I have the firm intention to start a social enterprise someday," "I am determined to have a direct social impact through my work in the future," and "I have very seriously thought of working in a social enterprise." The items were assessed on a seven-point Likert scale, with "1" representing "strongly disagree" and "7" representing "strongly agree."

\section{Data Analysis}

\subsection{Test of the Proposed Model}

Since all of our data was self-reported, we acknowledge the possibility of common method bias. Following the recommendation of Podsakoff and his colleagues (2003), a one-factor test was used to test for the presence of common method bias. In other words, in a factor analysis, one factor should not explain the variance across all items. If it does, then common method bias is present in the data. Of the five factors identified, the principal factor explained 29.5 percent of the variance. Since no single factor explained more than 50 percent of the variance, common method bias was not likely an issue in this data set (Podsakoff \& Organ 1986).

Table 1 shows the means, standard deviations, and correlations analysis results.

Table 1. Summary of descriptive and correlations analysis

\begin{tabular}{llllllllll}
\hline & Mean & s.d. & 1 & 2 & 3 & 4 & 5 & 6 & 7 \\
\hline 1.Gender & n.a. & n.a. & & & & & & & \\
2. Age & 15.3 & 1.14 & .06 & & & & & & \\
3. Race & n.a & n.a & -.05 & $-.18^{*}$ & & & & & \\
4. Empathic Concern & 3.80 & .67 & $.29^{* *}$ & .02 & -.07 & & & & \\
5. Perspective Taking & 3.58 & .69 & .04 & -.05 & -.08 & $.29^{* *}$ & & & \\
6. Social Justice Advocacy & 4.23 & 1.13 & $.22^{* *}$ & .06 & $-.21^{* *}$ & $.33^{* *}$ & $.29^{* *}$ & & \\
7. Ethical Sensitivity & 5.39 & .90 & $.21^{* *}$ & .00 & -.06 & $.43^{* *}$ & $.33^{* *}$ & $.46^{* *}$ & \\
8. Social Entrepreneurial & & & & & & & & & \\
Intention & 4.04 & 1.27 & .06 & -.02 & -.10 & $.29^{* *}$ & $.24^{* *}$ & $.47^{* *}$ & $.39^{* *}$ \\
\hline
\end{tabular}

For the test of the proposed hypotheses, path analysis was conducted using SmartPLS3 with 5000 re-samples (Peng \& Lai, 2012; Hair et al., 2012). The results were presented in Figure 1.

Hypothesis 1 predicted that social justice advocacy is positively related to SE intention. According to the figure, social justice advocacy was positively associated with $\mathrm{SE}$ intention $(\beta=.44, \mathrm{p}<.01)$. Thus, hypothesis 1 was supported.

Hypothesis 2 predicted that ethical sensitivity has a positive association with SE intention. The result indicated that ethical sensitivity is positively related to $\mathrm{SE}$ intention $(\beta=.30, \mathrm{p}<.01)$, supporting hypothesis 2 .

Hypothesis 3 proposed that empathic concern is positively related to social justice advocacy. The result demonstrated that empathic concern has a positive association with social justice advocacy $(\beta=.33, p<.01)$. Thus, hypothesis 3 was supported. 
Hypothesis 4 predicted that perspective taking is positively related to ethical sensitivity. Figure 1 indicated that perspective taking has a positive association with ethical sensitivity $(\beta=.22, \mathrm{p}<.01)$. Thus, hypothesis 4 was supported.

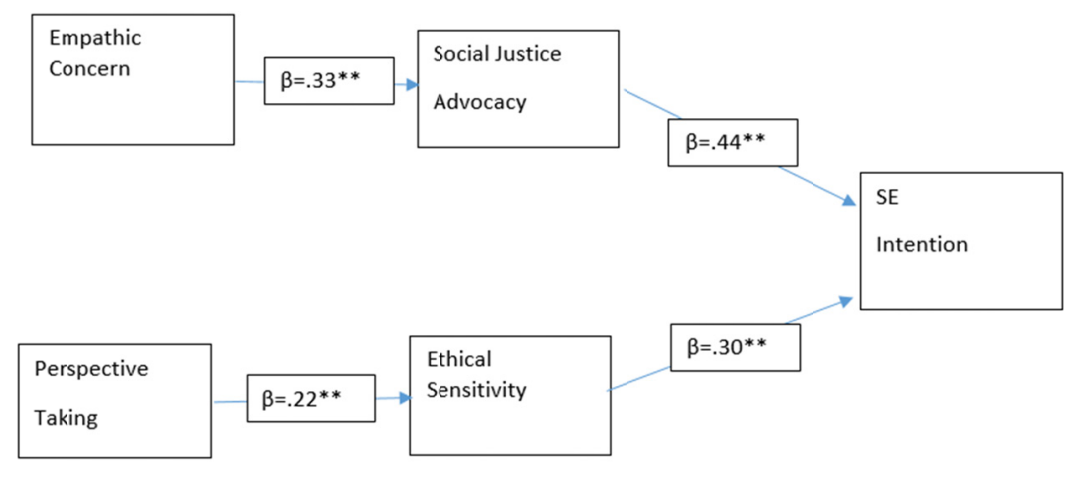

Figure 2. Path analysis results

\section{Discussion}

\subsection{Findings}

The objective of this study was to assess the effect of ethical sensitivity and social justice advocacy on SE intention and also, examined the effect of empathic concern and perspective taking on social justice advocacy and ethical sensitivity respectively. Another objective is to assess these relationships using the high school student population.

The results of the data analysis indicated that hypotheses 1-4 were all supported. The results revealed that high school students who scored a higher level of social justice advocacy showed stronger intention on social entrepreneurship. There have been no previous studies to examine this relationship. However, this result can be easily inferred. People with higher social justice advocacy are more likely to show prosocial behavior, which is a root of initiating social entrepreneurship.

Another finding showed that a high school student with a high level of ethical sensitivity showed higher SE intention. In past studies, ethical sensitivity was not highlighted as a crucial antecedent of SE intention. This finding implies that an individual who has high ethical sensitivity is more likely to recognize social injustice and become motivated to engage in such activities to solve social injustice by initiating social entrepreneurship.

The study also found that empathic concern is a significant antecedent of social justice advocacy. An individual who can sympathize with the suffering of others will show concern over the problem and engage in activities to solve the problem.

Another finding is that perspective taking is a significant antecedent of ethical sensitivity. This finding is not unique but replicates the findings of past studies. Perspective taking leads to more ethical decision making of employees (Cojuharenco \& Sguera, 2015) and the promotion of perspective taking influences children's morality (Cingel \& Krcmar, 2017).

Although we didn't propose the hypothesis, one interesting finding is that female students have higher ethical sensitivity $(\mathrm{r}=.22 * *)$ and social justice advocacy $(\mathrm{r}=.21 * *)$. These findings are consistent with past studies. Hadjicharalambous and Shi (2015) revealed that females are more likely to evaluate unethical and questionable practices as unethical, demonstrating higher ethical sensitivity.

\section{Conclusion}

\subsection{Contributions and Implications}

This study contributes to the existing literature on SE intention in several folds. First, this study first examined the SE intention of high school students. In particular, there have been no studies examining the SE intention of high school students. To our knowledge, this is the first study to examine the SE intention of high school students. Second, the current study is the first one to examine the impact of social justice advocacy on SE intention. This study found that people with higher social justice advocacy is more likely to engage in social entrepreneurship. Third, this study provides several implications for educators and social entrepreneurs. Our study finds that ethical sensitivity and social justice advocacy will foster SE intention among high school students. Unlike adult groups, high school students are still developing their ethical system and values and attitudes: towards social issues. 
Education and training programs can play a critical role in developing high school students' ethical systems or attitudes toward social justice. Many studies have demonstrated that education and training can foster ethical sensitivity and social justice advocacy even for college students (Miller et al., 2009; Nilsson et al., 2011). There should be more emphasis on ethics and social justice in the curricula of high schools.

Currently, various organizations exist (e.g., Ashoka, Skoll, Schwab foundation) to support social entrepreneurs. These organizations provide training, develop social entrepreneur community, offer grants or loans, and develop a network among stakeholders. They provide a wide variety of services, but their target audience does not encompass high school students. If an individual is exposed to social entrepreneurship at an earlier age, he or she is more likely to develop an interest in social entrepreneurship. Thus, these organizations need to expand their target audience to high school student groups.

\section{Limitations}

The current study must address its weaknesses. Firstly, one limitation of this study is the sole use of self-reported measures, which can cause common method bias. To confirm whether there is common method bias, we did one test which was suggested by Podsakoff et al. (2003), finding that no single factor explained more than 50 percent of the variance. Thus, common method bias was likely not an issue in our data set. However, future research needs to collect data from various sources to test the hypotheses.

Secondly, the participants for the study are high school students who reside in metropolitan areas in the east coast of the U.S. There will be limitations in generalizing the results of this study to populations of different ages or geographic areas.

Thirdly, we collected cross-sectional data to test the suggested hypotheses. The results showed that ethical sensitivity and social justice advocacy influence SE intention. However, there is a possibility of reverse causal relationship among the variables. To avoid this issue, future research needs to test this relationship by using longitudinal data.

\section{Future Research Issues}

This study targeted the population of high school students. Future research needs to replicate the findings in this study with different populations including college students and adult groups. This study considered ethical sensitivity and social justice advocacy as the prominent antecedents of SE intention. Future research needs to explore more possible antecedents of SE intentions such as the exposure to social entrepreneurship, the experience in purchasing social enterprise products, or the exposure to social problems. As it is mentioned in the limitations section, this study collected cross-sectional data which can cause a reverse causal relationship between the variables. Future research needs to collect longitudinal data to test the relationship between the antecedent and its consequences, avoiding the reverse causal relationship. We proposed that education and training programs can foster high school students' SE intentions. Future research needs to conduct an experiment to test whether a training program can foster high school students' SE intention.

\section{References}

Ajzen, I. (1991). The theory of planned behavior. Organizational Behavior and Human Decision Process, 50(2), 179-211. https://doi.org/10.1016/0749-5978(91)90020-T

Ajzen, I., \& Madden, T. J. (1986). Prediction of goal-directed behavior: Attitudes, intentions, and perceived behavioral control. Journal of Experimental Social Psychology, 22(5), 453-474. https://doi.org/10.1016/0022-1031(86)90045-4

Bacq, S., \& Alt, E. (2018). Feeling capable and valued: A prosocial perspective on the link between empathy and SE intentions. Journal of Business Venturing, 33(3), 333-350. https://doi.org/10.1016/j.jbusvent.2018.01.004

Batson, C. D. (2010). Empathy-induced altruistic motivation. In M. Mikulincer \& P. R. Shaver (Eds.), Prosocial Motives, Emotions, and Behavior: The Better Angels of Our Nature. Washington, DC., American Psychological Association.

Blum, L. (1991). Moral perception and particularity. Ethics, 101(4), 701-725. https://doi.org/10.1086/293340

Cavazos-Arroyo, J., Puente-Diaz, R., \& Agarwal, N. (2017). An examination of certain antecedents of SE intentions among mexico residents. Review of Business Management, 19(64), 180-199. https://doi.org/10.7819/rbgn.v19i64.3129

Cingel, D. P., \& Krcmar, M. (2017). Prosocial television, preschool children's moral judgments, and moral reasoning: the role of social moral institutions and perspective-taking. Communication Research, 46(3), 
355-374. https://doi.org/10.1177/0093650217733846

Cojuharenco, I., \& Sguera, F. (2015). When empathic concern and perspective taking matter for ethical judgment: the role of time hurriedness. Journal of Business Ethics, 130(3), 717-725. https://doi.org/10.1007/s10551-014-2259-8

Constantine, M. G., Hage, S. M., Kindaichi, M. M., \& Bryant, R. M. (2007). Social justice and multicultural issues: implications for the practice and training of counselors and counseling psychologists. Journal of Counseling \& Development, 85(1), 24-29. https://doi.org/10.1002/j.1556-6678.2007.tb00440.x

Davis, M. H. (1980). A multidimensional approach to individual differences in empathy. JSAS Catalog of Selected Documents in Psychology, 10, 1-19.

Edele, A., Dziobek, I., \& Keller, M. (2013). Explaining altruistic sharing in the dictator game: The role of affective empathy, cognitive empathy, and justice sensitivity. Learning and Individual Differences, 24, 96-102. https://doi.org/10.1016/j.lindif.2012.12.020

Eisenberg, N. (2000). Emotion, regulation and moral development. Annual Review of Psychology, 51(1), 665-697. https://doi.org/10.1146/annurev.psych.51.1.665

Ernst, K. (2012). Social entrepreneurs and their personality. In C. Volkmann, K. Tokarski, K. Ernst (Eds.), Social Entrepreneurship and Social Business. Gabler Verlag. https://doi.org/10.1007/978-3-8349-7093-0_3

FeldmanHall, O., Dalgleish, T., Evans, D., \& Mobbs, D. (2015). Empathic concern drives costly altruism. NeuroImage, 105, 347-356. https://doi.org/10.1016/j.neuroimage.2014.10.043

Fietzer, A. W., \& Ponterotto, J. (2015). A psychometric review of instruments for social justice advocacy attitudes. Journal for Social Action in Counseling and Psychology, 7(1), 19-40.

Fouad, N. A., Gerstein, L. H., \& Toporek, R. L. (2006). Social Justice and Counseling in Context. In R. L. Toporek, L. H. Gerstein, N. A. Fouad, G. Roysircar, \& T. Israel (Eds.), Handbook for Social Justice in Counselling Psychology: Leadership, Vision, and Action. Thousand Oaks, CA: Sage.

Hadjicharalambous, C., \& Shi, Z. (2015). Attitudes toward ethical sensitivity: Implications related to gender identity and personality. Journal of Legal, Ethical and Regulatory Issues, 18(3), 31-44.

Haidt, J. (2003). The moral emotions. In R. J. Davidson, K. R. Scherer, \& H. H. Goldsmith (Eds.), Handbook of Affective Sciences. Oxford, U.K: Oxford University Press.

Hair, J. F., Sarstedt, M., Pieper, T. M., \& Ringle, C. M. (2012). An assessment of the use of partial least squares structural equation modeling in market research. Journal of the Academy of Marketing Science, 40(3), 414-433. https://doi.org/10.1007/s11747-011-0261-6

Hess, J. L., Strobel, J., \& Brightman, A. (2017). The development of perspective-taking in an engineering ethics course. Journal of Engineering Education, 106(4), 534-563. https://doi.org/10.1002/jee.20175

Hockerts, K. (2015). The social entrepreneurial antecedents scale (SEAS): a validation study. Social Enterprise Journal, 11(3), 260-280. https://doi.org/10.1108/SEJ-05-2014-0026

Jimmieson, N. L., Peach, M., \& White, K. M. (2008). Utilizing the theory of planned behavior or inform change management: an investigation of employee intentions to support organizational change. Journal of Applied Behavioral Science, 44(2), 237-262. https://doi.org/10.1177/0021886307312773

Krueger, N. F., Reilly, M. D., \& Carsrud, A. L. (2000). Competing models of entrepreneurial intentions. Journal of Business Venturing, 15(5-6), 411-432. https://doi.org/10.1016/S0883-9026(98)00033-0

Lim, D., \& DeSteno, D. (2016). Suffering and compassion: the links among adverse life experiences, compassion, and prosocial behavior. Emotion, 16(2), 175-182. https://doi.org/10.1037/emo0000144

Linan, F., \& Chen, Y. (2009). Development and cross-cultural application of a specific instrument to measure entrepreneurial intentions. Entrepreneurship Theory and Practice, 33(3), 593-617. https://doi.org/10.1111/j.1540-6520.2009.00318.x

Linan, F., \& Fayolle, A. (2015). A systematic literature review on entrepreneurial intentions: citation, thematic analysis, and research agenda. International Entrepreneurship and Management Journal, 11(4), 907-933. https://doi.org/10.1007/s11365-015-0356-5

Mair, J., \& Noboa, E. (2006). Social entrepreneurship: How intentions to create a social venture are formed. In J. Mair, J. Robinson, \& K. Hockerts (Eds.), Social Entrepreneurship. Palgrave Macmillan, London, England. https://doi.org/10.1057/9780230625655_8 
Miller, M. J., Sendrowitz, K., Connacher, C., Blanco, S., de la Pena, C. M., Bernardi, S., \& Morere, L. (2009). College students' social justice interest and commitment: A social-cognitive perspective. Journal of Counseling Psychology, 56(4), 495-507. https://doi.org/10.1037/a0017220

Moeschberger, S. L., Ordonez, A., Shankar, J., \& Raney, S. (2006). Moving from contact to change: The act of becoming aware. In R. L. Toporek, L. H. Gerstein, N. A. Fouad, G. Roysircar, \& T. Israel (Eds.), Handbook for Social Justice in Counselling Psychology: Leadership, Vision, and Action. Thousand Oaks, CA: Sage.

Moll, J., Oliveira-Souza, R., \& Zahn, R. (2008). The neural basis of moral cognition: sentiments, concepts and values", Annals of the New York Academy of Sciences, 1124(10), 161-180. https://doi.org/10.1196/annals.1440.005

Nga, J., \& Shamuganathan, G. (2010). The influence of personality traits and demographic factors on social entrepreneurship start-up intentions. Journal of Business Ethics, 95(2), 259-282. https://doi.org/10.1007/s10551-009-0358-8

Nilsson, J. E., Schale, C. L., \& Khamphakdy-Brown, S. (2011). Facilitating trainees' multicultural development and social justice advocacy through a refugee/immigrant mental health program. Journal of Counseling \& Development, 89(4), 413-422. https://doi.org/10.1002/j.1556-6676.2011.tb02838.x

Peng, D. X., \& Lai, F. (2012). Using partial least squares in operations management research: A practical guideline of summary of past research. Journal of Operations Management, 30, 467-480. https://doi.org/10.1016/j.jom.2012.06.002

Piaget, J. (1932). The Moral Judgement of the Child. Harcourt Brace, Oxford, England.

Podsakoff, P. M., \& Organ, D. W. (1986). Self-reports in organizational research: problems and prospects. Journal of Management, 12(4), 531-544. https://doi.org/10.1177/014920638601200408

Podsakoff, P. M., MacKenzie, S., Lee, J., \& Podsakoff, N. (2003). Common method biases in behavioral research: A critical review of the literature and recommended remedies. Journal of Applied Psychology, 88(5), 879-903. https://doi.org/10.1037/0021-9010.88.5.879

Pohling, R. Bzdok, D., Eigenstetter, M. Stumpf, S., \& Strobel, A. (2016). What is ethical competence? The role of empathy, personal values, and the five factor model of personality in ethical decision-making. Journal of Business Ethics, 137(3), 449-474. https://doi.org/10.1007/s10551-015-2569-5

Prieto, L. C. (2011). The influence of proactive personality on SE intentions among African-Americans and Hispanic undergraduate students: the moderating role of hope. Academy of Entrepreneurship Journal, 17(2), 77-96.

Prieto, L. C., Phipps, S., \& Friedrich, T. L. (2012). Social entrepreneur development: and integration of critical pedagogy, the theory of planned behavior and the ACS model. Academy of Entrepreneurship Journal, 18(2), $1-15$.

Sparks, R. J., \& Hunt, S. (1998). Marketing researcher ethical sensitivity: Conceptualization, measurement and $\begin{array}{llll}\text { exploratory investigation. Journal of } & \text { 92-109. }\end{array}$ https://doi.org/10.1177/002224299806200207

Tangney, J., Stuewig, J., \& Mashek, D. J. (2007). Moral emotions and moral behavior. Annual Review of Psychology, 58, 345-372. https://doi.org/10.1146/annurev.psych.56.091103.070145

Tiwari, P., Bhat, A., \& Tikoria, J. (2017). An empirical analysis of the factors affecting SE intentions. Journal of Global Entrepreneurship Research, 7(9), 1-25. https://doi.org/10.1186/s40497-017-0067-1

Toti, J., \& Moulins, J. (2017). Ethical sensitivity: Conceptualization and new scale development. Recherche et Applications en Marketing, 32(3), 6-27. https://doi.org/10.1177/2051570717716562

Weng, H. Y., Fox, A. S., Hessenthaler, H. C., Stodola, D. E., \& Davidson, R. J. (2015). The role of compassion in altruistic helping and punishment behavior. PLoS One, 10(12). https://doi.org/10.1371/journal.pone.0143794

\section{Copyrights}

Copyright for this article is retained by the author(s), with first publication rights granted to the journal.

This is an open-access article distributed under the terms and conditions of the Creative Commons Attribution license (http://creativecommons.org/licenses/by/4.0/). 